\title{
Localization of ABCG5 and ABCG8 proteins in human liver, gall bladder and intestine
}

\author{
Eric L Klett*1, Mi-Hye Lee ${ }^{1}$, David B Adams², Kenneth D Chavin ${ }^{3}$ and \\ Shailendra B Patel ${ }^{1}$
}

Address: ${ }^{1}$ Division of Endocrinology, Diabetes and Medical Genetics, Medical University of South Carolina, STR 541, 114 Doughty Street, Charleston, South Carolina 29403, USA, 2Division of Gastrointestinal Surgery, Medical University of South Carolina, 96 Jonathan Lucas Street, CSB 211, Charleston, SC 29425, USA and ${ }^{3}$ Division of Transplant Surgery, Medical University of South Carolina, 96 Jonathan Lucas Street, CSB 404, Charleston, SC 29425, USA

Email: Eric L Klett* - klettel@musc.edu; Mi-Hye Lee - leemih@musc.edu; David B Adams - adamsdav@musc.edu; Kenneth D Chavin - chavinkd@musc.edu; Shailendra B Patel - patelsb@musc.edu

* Corresponding author

Published: 2I September 2004

BMC Gastroenterology 2004, 4:2I doi: 10.1 I86/I47|-230X-4-2 I
Received: 03 May 2004

Accepted: 21 September 2004

This article is available from: http://www.biomedcentral.com/l47I-230X/4/2I

(c) 2004 Klett et al; licensee BioMed Central Ltd.

This is an open-access article distributed under the terms of the Creative Commons Attribution License (http://creativecommons.org/licenses/by/2.0), which permits unrestricted use, distribution, and reproduction in any medium, provided the original work is properly cited.

\begin{abstract}
Background: The molecular mechanisms that regulate the entry of dietary sterols into the body and their removal via hepatobiliary secretion are now beginning to be defined. These processes are specifically disrupted in the rare autosomal recessive disease, Sitosterolemia (MIM 210250). Mutations in either, but not both, of two genes $A B C G 5$ or ABCG8, comprising the STSL locus, are now known to cause this disease and their protein products are proposed to function as heterodimers. Under normal circumstances cholesterol, but not non-cholesterol sterols, is preferentially absorbed from the diet. Additionally, any small amounts of non-cholesterol sterols that are absorbed are rapidly taken up by the liver and preferentially excreted into bile. Based upon the defects in sitosterolemia, ABCG5 and ABCG8 serve specifically to exclude non-cholesterol sterol entry at the intestinal level and are involved in sterol excretion at the hepatobiliary level.
\end{abstract}

Methods: Here we report the biochemical and immuno-localization of ABCG5 and ABCG8 in human liver, gallbladder and intestine using cell fractionation and immunohistochemical analyses.

Results: We raised peptide antibodies against ABCG5 and ABCG8 proteins. Using human liver samples, cell fractionation studies showed both proteins are found in membrane fractions, but they did not co-localize with caveolin-rafts, ER, Golgi or mitochondrial markers. Although their distribution in the sub-fractions was similar, they were not completely contiguous. Immunohistochemical analyses showed that while both proteins were readily detectable in the liver, ABCG5 was found predominately lining canalicular membranes, whereas ABCG8 was found in association with bile duct epithelia. At the cellular level, ABCG5 appeared to be apically expressed, whereas ABCG8 had a more diffuse expression pattern. Both ABCG5 and ABCG8 appeared to localize apically as shown by co-localization with MRP2. The distribution patterns of $A B C G 5$ and $A B C G 8$ in the gallbladder were very similar to each other. In the small intestine both $A B C G 5$ and $A B C G 8$ appear to line the brush border. However, at the level of the enterocyte, the cellular distribution patterns of $A B C G 5$ and $A B C G 8$ differed, such that $A B C G 5$ was more diffuse, but ABCG8 was principally apical. Using standard deglycosylation methods, ABCG5 and ABCG8 do not appear to be glycosylated, suggesting a difference between human and mouse proteins. 


\begin{abstract}
Conclusion: We report the distribution patterns of ABCG5 and ABCG8 in human tissues. Cell fractionation studies showed that both proteins co-fractionated in general, but could also be found independent of each other. As predicted, they are expressed apically in both intestine and liver, although their intracellular expression patterns are not completely congruent. These studies support the concept of heterodimerization of ABCG5 and ABCG8, but also support the notion that these proteins may have an independent function.
\end{abstract}

\section{Background}

The gastrointestinal tract is the initial barrier to dietary constituents and is important in regulating nutrient entry, as well as keeping non-nutrients out. Additionally, the hepatobiliary system acts as an additional filter to rapidly excrete such non-nutrients into bile, thus keeping the net retention of these potential toxins low. Mammals have evolved many mechanisms in the gastrointestinal tract to select out usable dietary constituents from those that maybe potentially toxic to the body. It is apparent that the ATP-binding cassette proteins (ABC proteins/transporters) are the machinery that mediate the ATP-dependent transport of a wide variety of substrates that range from xenobiotics to peptide fragments [1]. A subset of these $\mathrm{ABC}$ transporters, located in the canalicular membranes of mammalian liver, play key roles in bile formation and detoxification [1-3].

One of these processes involves the regulation of sterol entry and excretion. Whole body cholesterol homeostasis is a tightly regulated process, involving dietary absorption, de novo synthesis and hepatobiliary secretion. Sitosterolemia, a rare autosomal recessive disorder of sterol metabolism results in the disruption of dietary sterol entry and hepatobiliary sterol secretion [4-6]. Under normal circumstances, our diets contain equal amounts of plant sterols and cholesterol, but the plant sterols are specifically excluded from our bodies and only regulated amounts of cholesterol are retained. In Sitosterolemia, this exclusion is defective resulting in the retention of non-cholesterol sterols. Mutations in either, but not both, of two ABC transporters, ABCG5 and ABCG8, encoded by a single locus, $S T S L$, are known to cause this disease [7-9]. Based upon the genetics, as well as in vitro and in vivo data, these 'half-transporters' are proposed to function as obligate heterodimers. In vitro experiments have shown that both proteins are needed to be co-expressed for apical expression and that these may function as mutual chaperones in the ER for maturation $[10,11]$. In vivo experiments in mice have not been consistent. Using the Abcg5/Abcg8 double knockout mice, Graf et al has shown that by inoculating them with adenoviral constructs for Abcg5 and Abcg8 that both are required for expression of both proteins [11]. Additionally, Plosch et al and our group have constructed mouse models deficient in either Abcg5 [12] or Abcg8 [13] that show different biliary physiology than that of the Abcg5/Abcg8 double knockout mice. This suggests these proteins may have independent function(s) in addition to their function as heterodimers. However, to date, no reports of characterization and localization of the human proteins have been reported.

In this report, we examined the location of these two proteins using cellular fraction and immunohistochemical analyses of human liver, gallbladder and small intestine. We found a general concordance of co-expression of both proteins, but we also noted that ABCG5 and ABCG8 could be found in plasma membranes, as well as in intracellular membrane locations independent of each other. Additionally, deglycosylation of human liver membranes with peptidyl N-glycosidases did not alter the mobility of the proteins after SDS-PAGE, suggesting that these proteins may not be glycosylated in human liver. This differential localization suggests that perhaps ABCG5 and ABCG8 may have functions independent of each other, as well as functioning as heterodimers.

\section{Methods}

Tissue aquistion. Human liver donated for transplantation, but deemed unsuitable for transplantation on inspection by the transplant service (usually based upon a 'fatty' appearance) was obtained in accordance with IRB approval. As soon as the liver was deemed unsuitable (typically less than $10 \mathrm{~h}$ following harvesting) pieces were either snap-frozen in liquid nitrogen and stored at $-80^{\circ} \mathrm{C}$ or liquid nitrogen until use, or placed in ice-cold 2-methylbutane and stored in liquid nitrogen. Samples from more than nine different donors were used in these studies. Additionally, human gallbladders and segments of proximal small intestine were obtained from patients under going either laproscopic cholecystectomy or pancreatoduodenectomy (Whipple procedure). These tissues were directly taken from the operating room in normal saline on ice to be processed directly for frozen sectioning.

\section{Antibodies}

Anti-membrin, anti-transferrin, and anti-calnexin antibodies were obtained from Stressgen (Victoria, BC Canada), anti-caveolin antibody from BD Bioscience (San Diego, CA, USA), anti-MDR1 that also detects MDR2/3 (C219) from Centocor Inc. (Malvern, PA, USA), antiMRP2 (cMOAT) from Chemicon International 
(Temecula, CA, USA) and secondary antibodies were purchased from Jackson Immuno research (West Grove, PA, USA). Polyclonal rabbit anti-sera to human ABCG5 and ABCG8 peptides were generated in-house, using a 20-peptide immunogen from human ABCG5 (576-587, FQKYCSEILVVNEFYGNFTC, GenBank Accession number NP_071881) and a 22-peptide sequence from human ABCG8 (608-629, SRRTYKMPLGNLTIAVSGDKIL, GenBank Accession number NP_071882). The anti-sera were further purified using peptide affinity columns and stored at a concentration of $0.8 \mathrm{mg} / \mathrm{ml}$ in Immuno Pure Binding Buffer (Pierce, Rockford, IL, USA). For peptide blocking experiments the peptides were dissolved in DMSO (final concentration 30\%), incubated with the corresponding peptide for $11 / 2$ hours at $37^{\circ} \mathrm{C}$ then used for immunoblotting as described below.

\section{Membrane protein preparation}

Crude total membrane isolation was carried out with minor modifications as previously described [14]. All the procedures were carried out at $4^{\circ} \mathrm{C}$. Three grams of human liver were homogenized in homogenization buffer ( $5 \mathrm{mM}$ Tris pH7.5, $250 \mathrm{mM}$ sucrose, $1 \mathrm{mM}$ PMSF, $20 \mu \mathrm{g} / \mu \mathrm{l}$ of leupeptin and $1 \mu \mathrm{g} / \mu \mathrm{l}$ of aprotinin) by applying 10 strokes with a dounce homogenizer. The homogenate was centrifuged at $1000 \mathrm{~g}$ for 10 minutes, the pellet containing any undisrupted cells and nuclear debris were re-homogenized with one-half the initial volume of homogenization buffer, centrifuged at $1000 \mathrm{~g}$ for $10 \mathrm{~min}$ utes and this process was repeated once more. Supernatants were pooled and subjected to centrifugation at $100,000 \mathrm{~g}$ for 40 minutes. The resulting pellet, deemed the crude membrane fraction, was used as the starting material for Western blotting and fractionation experiments.

\section{Nycodenz gradient fractionation}

Human liver crude total membrane proteins were re-suspended in 30\% Nycodenz solution (Nycodenz in $5 \mathrm{mM}$ Tris-HCl pH 7.5 and $1 \mathrm{mM}$ EDTA). This suspension was loaded on top of a $40 \%$ Nycodenz solution cushion in an ultracentrifuge tube, overlaid by consecutive $23 \%, 20 \%$, $15 \%$ and $10 \%$ Nycodenz solutions and subjected to centrifugation at 39,000 rpm for 16 hours at $4{ }^{\circ} \mathrm{C}$ in a SW41 rotor (Beckman Instrument, Palo Alto, CA). After centrifugation, 800-1000 $\mu \mathrm{l}$ fractions were sequentially removed from the top, combined with two volumes of homogenization buffer (see above) and centrifuged at $39,000 \mathrm{rpm}$ at $4^{\circ} \mathrm{C}$ for 40 minutes to remove the Nycodenz. The resulting pellets were re-suspended in buffer $(25 \mathrm{mM}$ Tris-HCl pH 7.5, $150 \mathrm{mM} \mathrm{NaCl}, 0.1 \%$ Triton X-100 and $0.1 \%$ SDS, $1 \mathrm{mM}$ PMSF, $20 \mu \mathrm{g} / \mu \mathrm{l}$ of leupeptin and $1 \mu \mathrm{g} / \mu \mathrm{l}$ of aprotinin), the protein content determined by the method of Lowry and fractions analysed by SDS-PAGE. Equal amounts of protein $(25 \mu \mathrm{g})$ per lane were loaded.

\section{Sucrose gradient fractionation}

The procedure for membrane fractionation was essentially as described for the Nycodenz fractionation, except for the homogenization buffer used ( $25 \mathrm{mM}$ Tris pH6.8, $150 \mathrm{mM}$ $\mathrm{NaCl}, 1 \mathrm{mM}$ PMSF, $20 \mu \mathrm{g} / \mu \mathrm{l}$ of leupeptin and $1 \mu \mathrm{g} / \mu \mathrm{l}$ of aprotinin). The sucrose density gradient fractionation was modified as previously described [15-17]. Human liver crude membrane proteins were re-suspended in $1 \%$ Triton X100 buffer (25 mM Tris-HCl pH6.5, $150 \mathrm{mM} \mathrm{NaCl}$, $1 \%$ Triton X100, $1 \mathrm{mM}$ PMSF, $20 \mu \mathrm{g} / \mu \mathrm{l}$ of leupeptin and $1 \mu \mathrm{g} / \mu \mathrm{l}$ of aprotinin), adjusted to a final sucrose concentration of $40 \%$ and overlaid with a $15-30 \%$ linear sucrose gradient. The samples were subjected to centrifugation at $39,000 \mathrm{rpm}$ for 16 hours at $4^{\circ} \mathrm{C}$ in a SW41 rotor (Beckman Instrument, Palo Alto, CA, USA) and fractions collected from the top as described above. The proteins from fractions 1-4 from top of the tube were precipitated with acetone because these fractions did not contain sufficient protein for direct analysis. After protein concentrations were determined, equal amounts of proteins $(20 \mu \mathrm{g})$ from each fraction were resolved by SDS-PAGE.

\section{Immunoblotting}

Proteins resolved by SDS-PAGE were transferred onto nitrocellulose membranes. Membranes were then blocked for 1 hour in 5\% dry milk in PBS-T (Phosphate Buffered saline and $0.1 \%$ Tween 20 ) and incubated with primary antibody against either ABCG5 or ABCG8 in 5\% milk in PBS-T overnight at $4{ }^{\circ} \mathrm{C}$. Blots were washed three times for 5 minutes in TBS-T (Tris Buffered Saline/0.1\% Tween-20) with $150 \mathrm{mM} \mathrm{NaCl}$, incubated with goat-anti-rabbit conjugated HRP antibodies (1:10000 dilution), washed for three times 5 minutes and developed with Western Lightning ${ }^{\circledR}$ Chemiluminescence Reagent Plus (Perkin Elmer Life Sciences, Inc. Boston, MA, USA).

\section{Immunohistochemical analysis and microscopy}

Snap-frozen liver, gallbladder and intestine tissues were used to cut $8 \mu \mathrm{m}$ thick frozen sections, air-dried for 30 minutes onto glass slides and kept at $-80^{\circ} \mathrm{C}$ until used. The slides were stained with hematoxylin, rinsed with PBS three times, fixed for 10 minutes with cooled methanol at $-20^{\circ} \mathrm{C}$ and rinsed with PBS three times. The slides were treated with blocking solution (10\% donkey serum in 0.1 $\mathrm{M}$ glycine/PBS) for 30 minutes at room temperature and incubated with primary antibody overnight at $4{ }^{\circ} \mathrm{C}$. The slides were washed with PBS and incubated with secondary antibody (goat-anti-rabbit conjugated with $\mathrm{Cy}^{\mathrm{rm}}$ or rhodamine or FITC) for 20-30 minutes at room temperature, rinsed with PBS three times and examined under an Olympus BX-5 confocal microscope with Fluoview. 


\section{Results \\ Identification of ABCG5 and ABCG8 in crude total membrane preparations of human liver}

Peptide antibodies were raised against human ABCG5 and human ABCG8 and affinity purified prior to use (see Methods). The immunogen peptides used for the antibodies were selected since they were sequences that lay outside of the predicted transmembrane domains and based upon antigenicity.Western blotting experiments (Figure 1A) showed that both anti-ABCG5 and anti-ABCG8 antibodies bound to $\sim 75 \mathrm{kDa}$ proteins in human liver crude membranes. Pre-immune sera did not detect the $\sim 75 \mathrm{kDa}$ expected bands. Pre-incubation of the immune antibodies with the peptides against which they were raised abolished specific binding (Figure 1B). For anti-ABCG5 $5 \mu \mathrm{g}$ of peptide was needed to block $1 \mu \mathrm{g}$ of antibody and for antiABCG8 $12.5 \mu \mathrm{g}$ of peptide was needed to block $1 \mu \mathrm{g}$ of antibody. Interestingly, a $\sim 60 \mathrm{kDa}$ band was detected using the anti-ABCG8 antibody whose signal is abolished when incubated with the peptide from which the antibody was raised (Figure $1 \mathrm{~B}$ and 1C, arrow indicated band). The significance of this is unclear at present. These antibodies were also tested against mouse and rat liver membrane preparations and no significant cross-reactivity was detected except for faint bands seen with antiABCG5 in mouse liver samples (Figure 1A, tracks 3 and 4). No other bands were detected above the $150 \mathrm{kDa}$ marker in all western blots. Interestingly, while these proteins are predicted to be N-glycosylated [8,9], only single bands in the appropriate molecular weight range were detected and no higher molecular bands were observed. To investigate whether these proteins are glycosylated, crude membrane fractions were digested with EndoH, PNGase F and examined for alterations in gel migration by SDS-PAGE (Figure 1C). Although the mobility of a known glycoprotein, transferrin, was increased in the same fractions following deglycosylation, there was no change in the mobility of ABCG5 or ABCG8 (Figure 1C).

\section{Localization of ABCG5 and ABCG8 by Nycodenz and Sucrose gradient fractionation of human liver}

Crude total membrane proteins from human liver were fractionated by Nycodenz gradient centrifugation and examined for localization markers by western blot analyses (Figure 2A). After Nycodenz gradient centrifugation, ABCG5 (fractions 9-10) and ABCG8 (fractions 6-11) were found to have a broad range of distribution and appeared to be distributed in a pattern similar to calnexin (an ER membrane marker, fractions 5-10), Cytochrome C (a mitochondrial marker, fractions 4-9), transferrin (a plasma membrane marker, fractions 1-11), caveolin (fractions 6-10) and MDR1 (an apical membrane marker, fractions 4-10). ABCG5 and ABCG8 did not co-localize with cis-Golgi (Figure 2A) markers.
To examine whether ABCG5 and ABCG8 were associated with membrane rafts, total membrane proteins from human liver were solubilized with ice-cold 1\% Triton X100 detergent and fractionated by sucrose density gradient centrifugation (Figure $2 \mathrm{~B}$ ). Fractionation resulted in two Triton X-100 insoluble complexes, as judged by the clarity of the gradient fractions. The first was found in the low-density range (15-20\% sucrose, fractions 2-6, Figure $2 \mathrm{~B})$ and the second in the high-density range $(40 \%$ sucrose, fractions 10-12, Figure 2B). Caveolin-rich fractions localized to the low-density range (Figure $2 \mathrm{~B}$, fractions 2-6). However, ABCG5 and ABCG8 were detected in the high-density fractions, F10-12, along with transferrin (fractions 5-12) and MDR1 (fractions 9-11). Calnexin or cytochrome $\mathrm{C}$, under these conditions did not co-localize with either ABCG5 or ABCG8. Note that the majority of the ABCG5 and ABCG8 were present in the densest fractions, F11-12. Under these conditions, membrin, a cisGolgi membrane marker, was also detected in fraction 12.

Thus, ABCG5 and ABCG8 have significant overlap with each other suggesting co-localization. However, these proteins did not seem to co-localize with any specific membrane marker except transferrin, when two different methods of fractionation were utilized.

\section{Immunohistochemical localization of ABCG5 and ABCG8 in human liver}

It has been shown previously that ABCG5 and ABCG8 are expressed only in the liver and intestine $[8,9]$. To further characterize the location of ABCG5 and ABCG8 in human liver, immunohistochemical analyses were performed on frozen serial sections of human liver. Pre-immune sera were used as negative controls. The distribution of the two proteins appeared to be divergent not only histologically, but also at the cellular level. From a histological point of view, ABCG5 was detected along sinusoidal tracts (Figure $3 \mathrm{~A}$, upper panel) whereas ABCG8 was detected within the cells lining the bile ducts (Figure 3B, upper panel). At higher magnification, ABCG5 was detected along bile canaliculi and at the cellular level appeared to be an apically expressed (Figure 3A, lower panel). However, the distribution of ABCG8 at the cellular level appeared more diffuse consistent with plasma membrane expression and perhaps in intracellular membranes (Figure 3B, lower panel). Expression of ABCG5 within intracellular vesicular compartments could not be excluded by the techniques employed. To confirm an apical location of ABCG5 and ABCG8 immunohistochemical co-localization studies were carried out using an antibody against a known apical transporter (MRP2) in the liver. As shown in Figure 4, ABCG5 and ABCG8 have significant overlap in expression with MRP2 (panels A and B, respectively). 




\section{Immunohistochemical localization of ABCG5 and ABCG8 in human gall bladder}

Serial sections of human gall bladder were incubated with each antibody and pre-immune serum was used as a negative control. Both ABCG5 and ABCG8 were detected in the epithelium of gall bladder mucosa (Figure 5A and 5B). At higher magnification, the cellular distribution of the signals detected was similar and showed a diffuse cytoplasmic distribution (Figure 5A and 5B).
Immunohistochemical localization of ABCG5 and ABCG8 in human small intestine

Both ABCG5 and ABCG8 were detected in the apical surfaces of the enterocytes in biopsy samples of the small intestine (Figure 6A and 6B, upper panels). However, at higher magnification the cellular distribution of ABCG5 appeared more diffuse (Figure 6A, lower panel) whereas ABCG8 was expressed apically (Figure 6B, lower panel). This divergent pattern was seen in all of the serial sections analyzed. 
A.
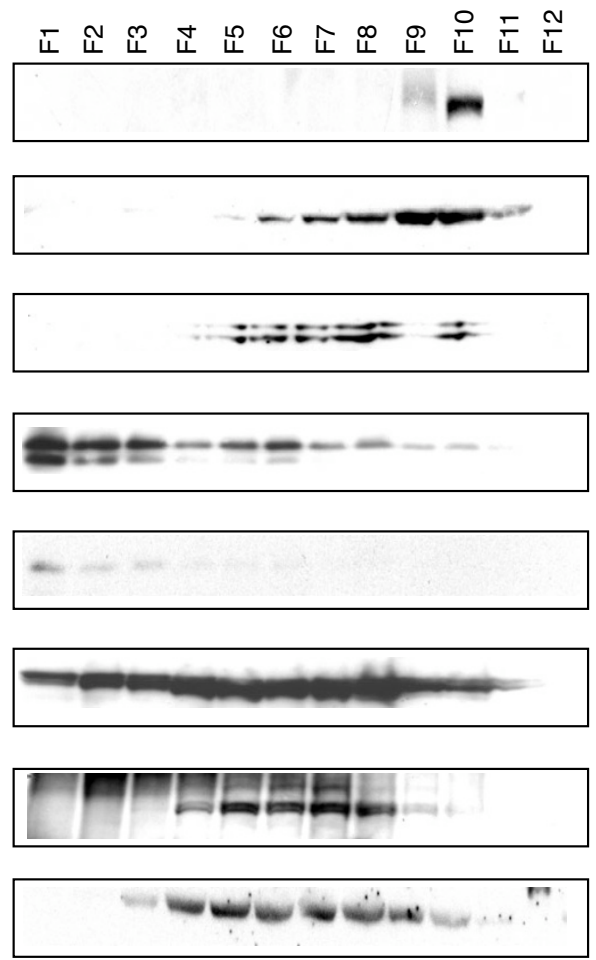

B.



Calnexin



Caveolin

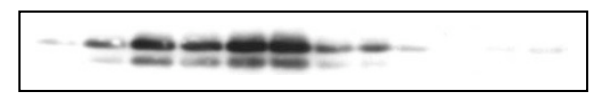

Membrin

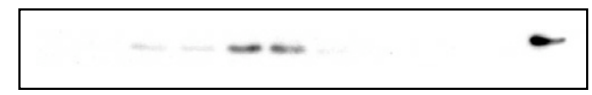

Transferrin

MDR1

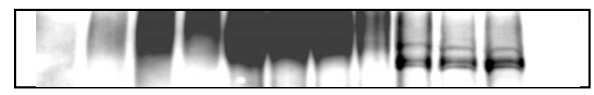

Cyto C

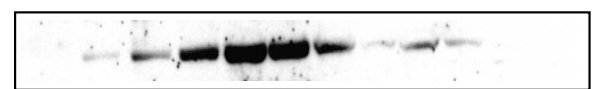

\section{Figure 2}

Subcellular localization of ABCG5 and ABCG8 in human liver. Panel A shows the Nycodenz gradient fractionation and panel $B$ the Triton $\mathrm{X}-100 /$ sucrose gradient fractionation. A representative result from each of these is shown. $\mathrm{FI}-\mathrm{FI} 2$ represents serial fractions collected from the top of the tube. Proteins from each of these fractions were separated by SGS-PAGE, western blotted and probed for the proteins as indicated on the figure. Calnexin (ER marker), membrin (Golgi marker) and caveolin (raft marker) did not co-localize with ABCG5/ABCG8 when both biochemical fractionation patterns are compared. However, MDRI (apical membrane marker) and transferrin (plasma membrane marker) showed some consistency with ABCG5/ABCG8 co-localizations (tracks F9-10, panel A and FII, panel B).

\section{Discussion}

In this study, we report the localization of ABCG5 and ABCG8 in human liver, gall bladder and intestine. Our studies showed that these proteins are highly specific in the cells they are expressed. In the liver, expression is seen in cells lining the hepatobiliary tracts, both hepatocytes and ductal cells. In the intestine, robust expression was seen only in the villus enterocyte layers. In the gall bladder, expression was confined to the epithelial cells lining the lumen. However, some differences in the distribution of ABCG5 and ABCG8 within these tissues were apparent. In the liver, ABCG8 was highly expressed in the hepatocytes lining the bile ducts, whereas ABCG5 was more robustly expressed in hepatocytes lining the cannaliculae. In fractionation studies, using two different methods of separation, the distribution of ABCG5 and ABCG8 was compatible with both proteins potentially acting as heterodimers. However, we also noted that there were fractions where only one of these proteins, but not the other was detected. This could be an artefact, with one antibody 
A.
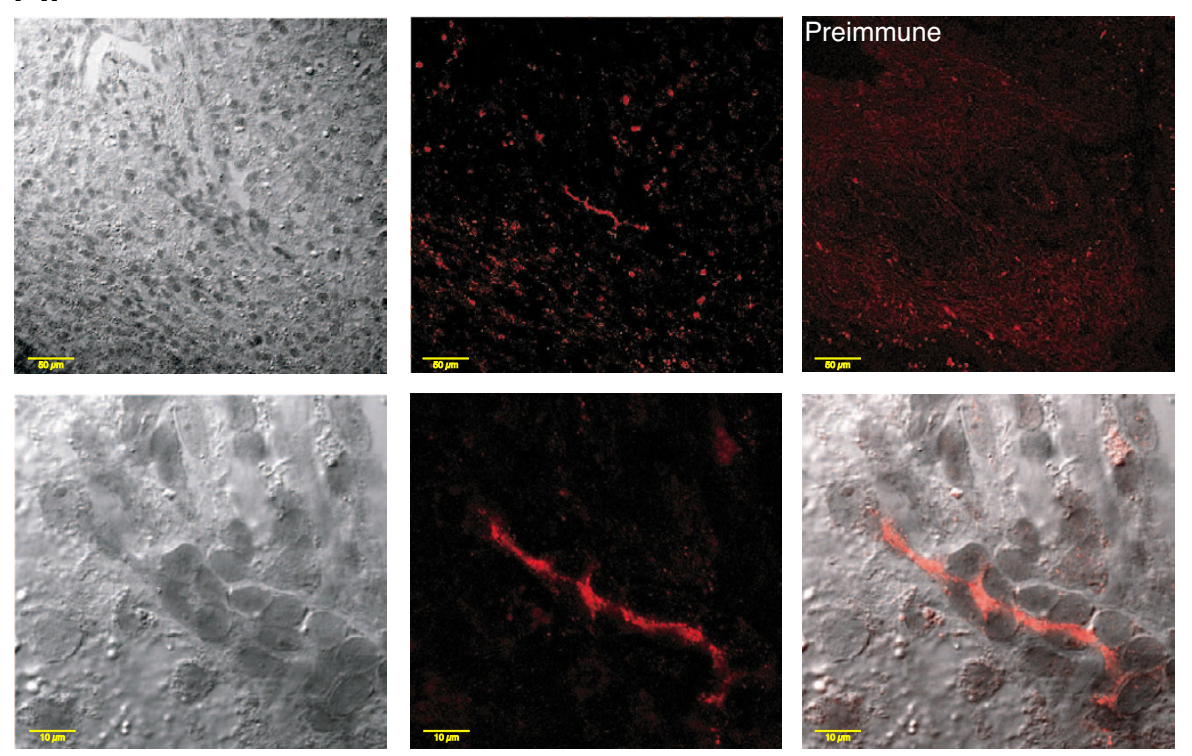

B.


\section{Figure 3}

Immunolocalization of ABCG5 and ABCG8 in human liver sections. Panel A shows the staining pattern of ABCG5 and panel $B$ that for ABCG8. The pre-immune controls for both antibodies are as marked and shown in the top right hand corners of each panel. The top panels of each section are at low magnification (bar is $50 \mu \mathrm{m}$ ) and the bottom panels at high magnification $(10 \mu \mathrm{m})$. The images for ABCG5 and ABCG8 were visualised with red and green colors respectively using Adobe Photoshop (Adobe, Cupertino, CA). The left panels show hematoxylin stained phase contrast images and the middle panels show the fluorescence images after immune serum staining. The bottom right panel of each section shows the merged images of phase contrast and the fluorescence signals. ABCG5 was readily detectable in canalicular cells and at higher magnification seemed to be apical in expression (panel A). On the other hand, ABCG8 was more readily detectable in cells lining the bile ducts (panel B, top panels), as well as in canalicular cells; although its cellular expression appeared more diffuse (see Text for discussion). 

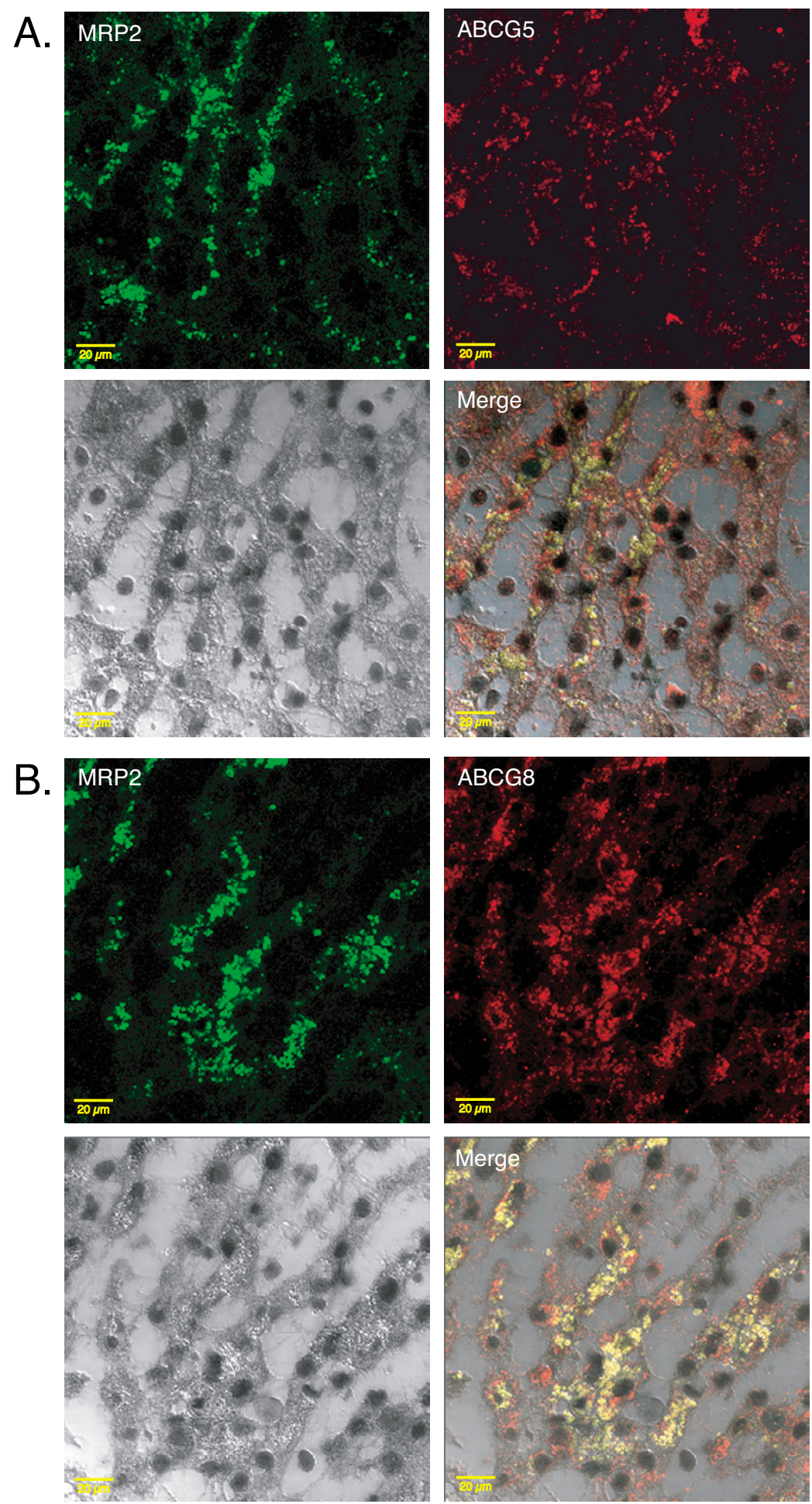

\section{Figure 4}

Co-localization of ABCG5 and ABCG8 with MRP2 by immunohistochemistry. Liver sections were simultaneously incubated with either the combination of anti-ABCG5/MRP2 or anti-ABCG8/MRP2. Panel A shows staining patterns of MRP2 and $A B C G 5$ independently (upper portion) then merged together (lower right) with what appears to be similar over-lapping expression patterns. Likewise MRP2 and ABCG8 expression patterns appear to over lap as well as shown in panel B. Bar is 20 $\mu \mathrm{m}$. 
A.
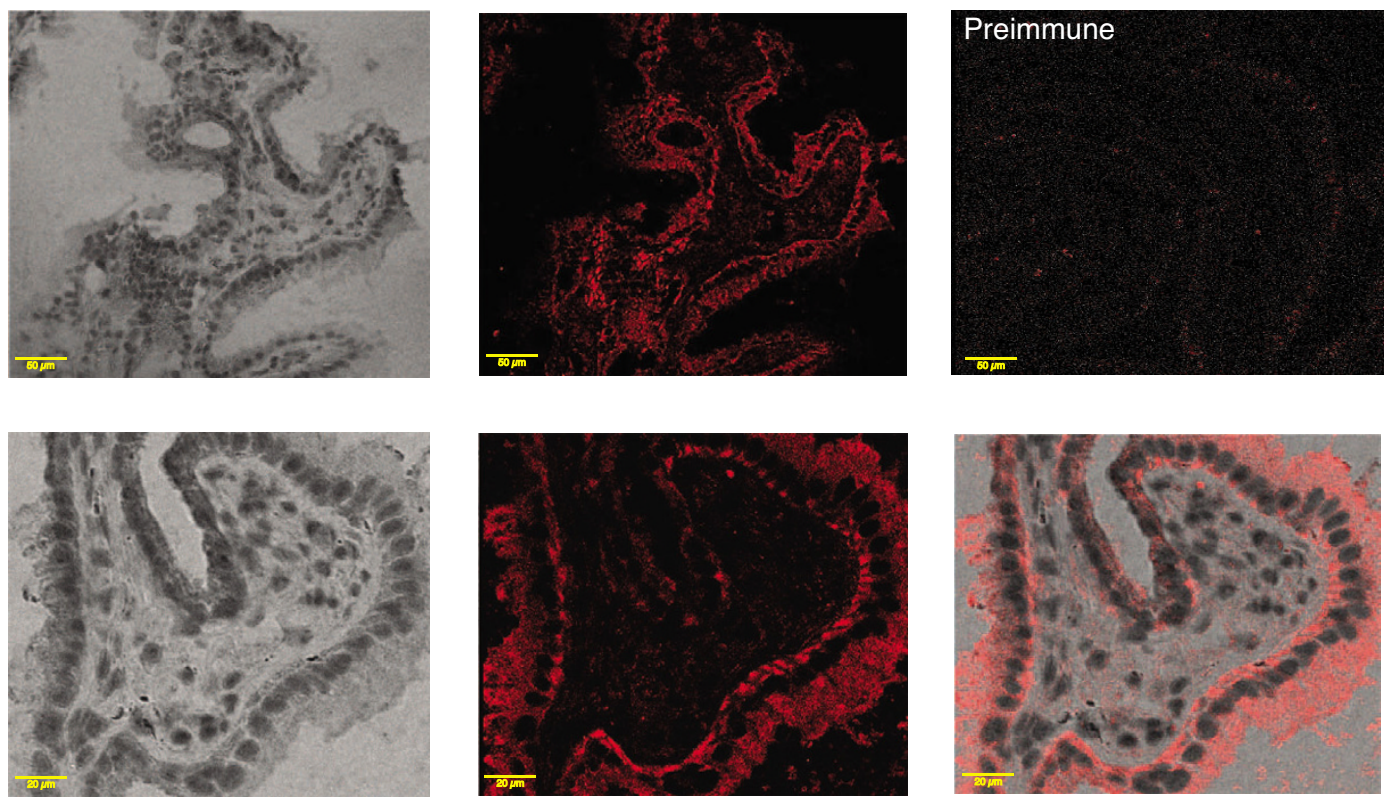

B.


\section{Figure 5}

Immunolocalization of ABCG5 and ABCG8 in human gall bladder sections. Gall bladder surgical samples were stained for $A B C G 5$ (panel $A$, red staining) or ABCG8 (panel $B$, green staining). The layout is as indicated for figure 3 . Both $A B C G 5$ and $A B C G 8$ appeared to be confined to the epithelial cells lining the lumen and no significant staining in any of the deeper cell layers was detected. At the cellular level, both proteins seem to be diffusely expressed within the cell and at plasma membrane. A strict apical expression was not observed for either of these proteins. 

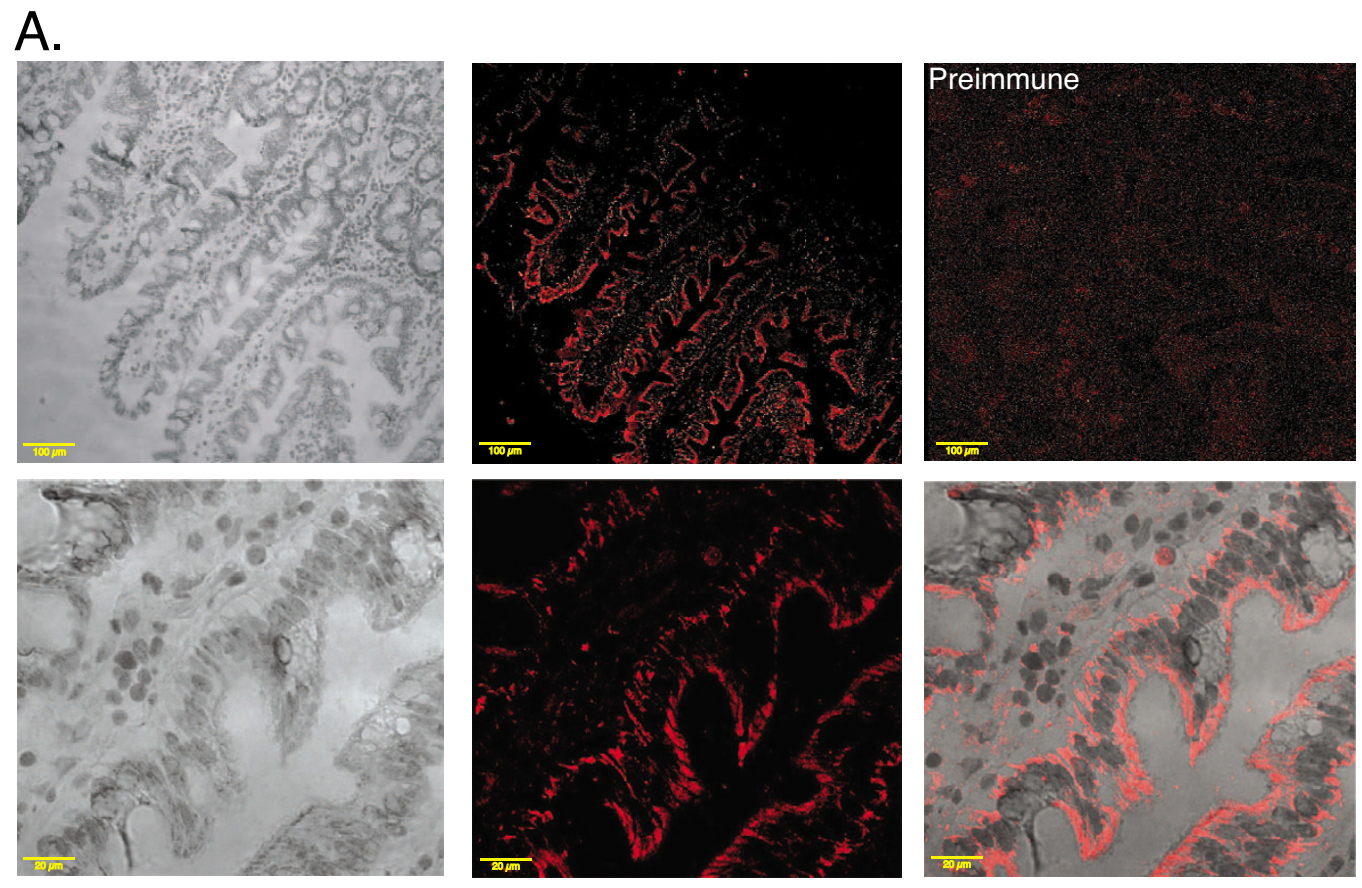

B.
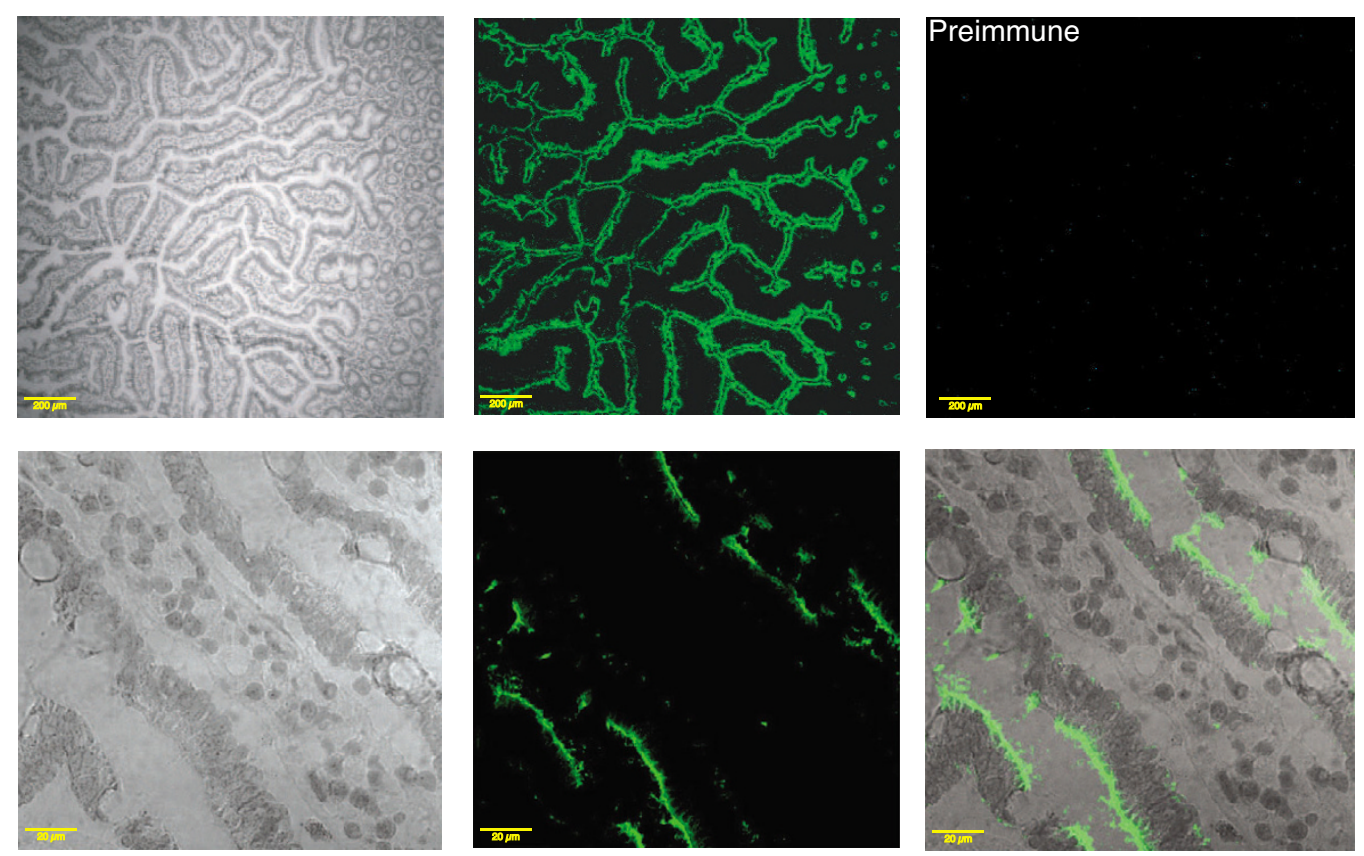

\section{Figure 6}

Immunolocalization of ABCG5 and ABCG8 in human intestinal sections. Human intestinal surgical samples were stained with $A B C G 5$ (panel $A$, red staining) or $A B C G 8$ (panel $B$, green staining). The layout is as indicated for figure 3 . At the cellular level, $A B C G 5$ was expressed in a more diffuse pattern (panel $A$, see bottom right hand panel). In contrast, $A B C G 8$ was expressed in the apical surfaces of the enterocytes (panel B, bottom right hand panel). Both proteins seemed to be expressed only in the enterocytes lining the villi and no significant expression was detected in any of the other cell layers. 
being a better reagent, or that this pattern could truly reflect that each of these proteins can also exist independently, perhaps as homodimers. Overall, the distribution patterns of ABCG5 and ABCG8 in these cellular fractionations were similar to that observed with the plasma membrane marker transferrin and apical membrane marker MDR1. Additionally, immunohistochemical analyses show that ABCG5 and ABCG8 are apically expressed in the liver, gall bladder and intestine. In the liver ABCG5 and ABCG8 also appear to co-localize with the known apical protein MRP2. This confirms previous data from Graf et al, using in vitro expression in WIF-B cells [10], and support the contention that ABCG5 and ABCG8 are plasma membrane proteins.

These data would suggest that expression of these proteins might not be wholly dependent upon mutual co-expression, as has been reported for the mouse and in in vitro studies $[10,11]$. However, one note of caution should be expressed. All of the liver samples analyzed were obtained because they were unsuitable for transplantation. Most livers were considered to be 'fatty' livers. While these livers were not effectively diseased, that fact that they had fatty infiltrates may have influenced the normal expression of these two half-transports. Thus, confirmation in normal human liver samples will be needed, though this may not be feasible.

With that reservation in mind, our data do have important implications for sterol trafficking in humans.

Firstly, the relatively robust and highly specific expression of ABCG5 and ABCG8 in gall bladder epithelium confirms the important role of this organ in regulating biliary secretion. In addition to the production of bile by the liver, the gall bladder may be able to further regulate the sterol content of bile, via ABCG5/ABCG8 activity. A similar pattern of expression has been reported in canine gall bladder epithelial cell culture and these data confirm these findings in human gall bladder [18].

Secondly, the differences in expression patterns of ABCG5 and ABCG8 in liver, gall bladder and intestine, though subtle, seem to indicate the several important possibilities. It is not clear which organ is of paramount importance in the human in regulating non-cholesterol sterol retention. And it is not clear if ABCG5 and ABCG8 play a significant role in determining cholesterol entry at the intestinal level, though they seem to be implicated strongly as determining sterol excretion at the level of the hepato-biliary system. In mice deficient for Abcg5/Abcg8 or Abcg5, cholesterol absorption rates were not dramatically affected $[12,19,20]$. Hepatobiliary excretion of all sterols was significantly (but not completely) reduced. In mice singly deficient for Abcg 5 or Abcg8, some differences have been reported [12,13]. In Abcg5 KO mice, following LXR activation, sterol excretion in bile was comparable to wild-type mice, though it is not clear if this also restored plant sterol excretion. In contrast, although cholesterol absorption studies for Abcg8 KO mouse have not been reported, biliary excretion of cholesterol was dramatically reduced and no stimulation of excretion was observed after forced bile acid infusions. While all of these data have been reported using different protocols (LXR activation, bile acid infusions, or static gall bladder puncture), these data suggest that there exist other pathways for sterol trafficking in both liver and intestine. At present it would be speculative to assume that these 'other' pathways involve ABCG5 or ABCG8 as homodimers, but this possibility is supported by the circumstantial evidence of separate patterns of expression of human ABCG5 and ABCG8 in these tissues.

Finally, although rodent sterolins are glycosylated and in vitro glycosylation is readily demonstrable, human ABCG5 and ABCG8 did not appear to be glycosylated as judged by deglycosylation-migration assays. It is possible that this technique is insensitive and these proteins are glycosylated. Alternatively, it is possible that the antibodies we have raised only react with unglycosylated forms and thus fail to detect the glycosylated forms. With respect to the first issue, deglycosylation-migration has been demonstrated to detect mouse glycosylated proteins and since these proteins are highly conserved, this possibility seems remote. With respect to the second possibility, if our antibodies were exclusively detecting unglycosylated (and presumably immature forms), the apical patterns of expression of these proteins in both the liver and intestine would seem to suggest that these proteins seem to traffic to these specialized membranes normally. In the absence of an independent method, and the lack of a direct assay for function, whether these proteins form an active heterodimer can not be resolved at present.

\section{Conclusion}

In summary, we report the first immunolocalization of ABCG5 and ABCG8 in human liver, gall bladder and intestine. Our data show that these proteins are located in membranes and can have an apical expression in all of these tissues. Biochemical, as well as immunolocalization studies show that while both proteins co-localize in general, they can also seem to have expression patterns that may be independent of each other.

\section{Competing interests}

None declared.

\section{Authors' contributions}

ELK and MHL performed the experiments, KDC and DBA provided the liver and surgical samples respectively SBP 
was responsible for supervision, data analyses and obtaining funding for these experiments. ELK and SBP wrote the paper.

\section{Acknowledgements}

Grants from the NIH, HL606I62 (SBP) and by NIH Postdoctoral Training Grant T32 HL07260 (ELK) supported this work. We would like to thank Brenda Baldwin, FNP for her assistance in obtaining consent from donor patients.

\section{References}

I. Elferink RO, Groen AK: Genetic defects in hepatobiliary transport. Biochim Biophys Acta 2002, I 586: I 29- I 45.

2. Ortiz DF, Li S, lyer R, Zhang X, Novikoff P, Arias IM: MRP3, a new ATP-binding cassette protein localized to the canalicular domain of the hepatocyte. Am J Physiol 1999, 276:GI493-500.

3. Kipp $H$, Arias IM: Trafficking of canalicular $\mathbf{A B C}$ transporters in hepatocytes. Annu Rev Physiol 2002, 64:595-608.

4. Bhattacharyya AK, Connor WE: Beta-sitosterolemia and xanthomatosis. A newly described lipid storage disease in two sisters. Journal of Clinical Investigation 1974, 53:1033-1043.

5. Rao MK, Perkins EG, Connor WE, Bhattacharyya AK: Identification of beta-sitosterol, campesterol, and stigmasterol in human serum. Lipids 1975, 10:566-568.

6. Salen G, Shefer S, Nguyen L, Ness GC, Tint GS, Shore V: Sitosterolemia. Journal of Lipid Research 1992, 33:945-955.

7. Lu K, Lee M-H, Hazard S, Brooks-Wilson A, Hidaka H, Kojima H, Ose L, Stanlenhoef AFH, Mietinnen T, Bjorkhem I, Brukert E, A. Pandya., Brewer HB, Salen G, Dean M, Srivastava A, Patel SB: Two genes that map to the STSL locus cause sitosterolemia: Genomic structure and spectrum of mutations involving sterolin-I and sterolin-2, encoded by ABCG5 and ABCG8 respectively. American Journal of Human Genetics 200I, 69:278-290.

8. Lee M-H, Lu K, Hazard S, Yu H, Shulenin S, Hidaka H, Kojima H, Allikmets R, Sakuma N, Pegoraro R, Srivastava AK, Salen G, Dean M, Patel $S B$ : Identification of a gene, ABCG5, important in the regulation of dietary cholesterol absorption. Nature Genetics 2001, 27:79-83.

9. Berge KE, Tian H, Graf GA, Yu L, Grishin NV, Schultz J, Kwiterovich $\mathrm{P}$, Shan B, Barnes R, Hobbs $\mathrm{HH}$ : Accumulation of dietary cholesterol in sitosterolemia caused by mutations in adjacent $A B C$ transporters. Science 2000, 290: 1771 - 1775.

10. Graf GA, Li WP, Gerard RD, Gelissen I, White A, Cohen JC, Hobbs $\mathrm{HH}$ : Coexpression of ATP-binding cassette proteins ABCG5 and $A B C G 8$ permits their transport to the apical surface. J Clin Invest 2002, I I 0:659-669.

II. Graf GA, Yu L, Li WP, Gerard R, Tuma PL, Cohen JC, Hobbs HH: ABCG5 and ABCG8 are obligate heterodimers for protein trafficking and biliary cholesterol excretion. J Biol Chem 2003, 278:48275-48282.

12. Plosch T, Bloks VW, Terasawa Y, Berdy S, Siegler K, Van Der Sluijs F, Kema IP, Groen AK, Shan B, Kuipers F, Schwartz M: Sitosterolemia in ABC-Transporter G5-deficient mice is aggravated on activation of the liver-X receptor. Gastroenterology 2004, I 26:290-300.

13. Klett EL, Lu K, Kosters A, Vink E, Lee MH, Altenburg M, Shefer S, Batta AK, Yu H, Chen J, Klein R, Looije N, Oude-Elferink R, Groen AK, Maeda N, Salen G, Patel SB: A mouse model of sitosterolemia: absence of Abcg8/sterolin-2 results in failure to secrete biliary cholesterol. BMC Med 2004, 2:5.

14. Garver WS, Heidenreich RA, Erickson RP, Thomas MA, Wilson JM: Localization of the murine Niemann-Pick CI protein to two distinct intracellular compartments. J Lipid Res 2000, 4I:673-687.

15. Brown DA, Rose JK: Sorting of GPI-anchored proteins to glycolipid-enriched membrane subdomains during transport to the apical cell surface. Cell 1992, 68:533-544.

16. Lisanti MP, Scherer PE, Vidugiriene J, Tang Z, Hermanowski-Vosatka A, Tu YH, Cook RF, Sargiacomo M: Characterization of caveolinrich membrane domains isolated from an endothelial-rich source: implications for human disease. I Cell Biol 1994, 126: I||-126.
17. Sargiacomo M, Sudol M, Tang Z, Lisanti MP: Signal transducing molecules and glycosyl-phosphatidylinositol-linked proteins form a caveolin-rich insoluble complex in MDCK cells. J Cell Biol 1993, I 22:789-807.

18. Tauscher A, Kuver R: ABCG5 and ABCG8 are expressed in gallbladder epithelial cells. Biochem Biophys Res Commun 2003, 307:1021-1028.

19. Yu L, Hammer RE, Li-Hawkins J, Von Bergmann K, Lutjohann D, Cohen JC, Hobbs HH: Disruption of Abcg5 and Abcg8 in mice reveals their crucial role in biliary cholesterol secretion. Proc Natl Acad Sci U S A 2002, 99:16237-16242.

20. Yu L, Von Bergmann K, Lutjohann D, Hobbs HH, Cohen JC: Selective sterol accumulation in ABCG5/ABCG8 deficient mice. J Lipid Res 2004, 45:301-307.

\section{Pre-publication history}

The pre-publication history for this paper can be accessed here:

http://www.biomedcentral.com/1471-230X/4/21/pre pub
Publish with Bio Med Central and every scientist can read your work free of charge

"BioMed Central will be the most significant development for disseminating the results of biomedical research in our lifetime. "

Sir Paul Nurse, Cancer Research UK

Your research papers will be:

- available free of charge to the entire biomedical community

- peer reviewed and published immediately upon acceptance

- cited in PubMed and archived on PubMed Central

- yours - you keep the copyright

Submit your manuscript here:

http://www.biomedcentral.com/info/publishing_adv.asp
BiolMedcentral 